\title{
Laser Cutting of Carbon Fiber Reinforced Plastics (CFRP and CFRTP) by IR Fiber Laser Irradiation
}

\author{
Hiroyuki Niino $^{* 1,2}$, Yoshihisa Harada ${ }^{* 1,2}$, Kenji Anzai ${ }^{* 1,3}$, Masafumi Matsushita ${ }^{* 1,4}$, Koichi Furukawa ${ }^{* 1,4}$, \\ Michiteru Nishino ${ }^{* 1,5}$, Akira Fujisaki ${ }^{* 1,6}$, and Taizo Miyato ${ }^{* 1,6}$ \\ ${ }^{* 1}$ Advanced Laser and Process Technology Research Association (ALPROT), Tokyo, Japan, \\ ${ }^{* 2}$ National Institute of Advanced Industrial Science and Technology (AIST), Tsukuba, Japan, \\ *3 AMADA MIYACHI CO., LTD., Noda, Japan, \\ ${ }^{*}$ Shin Nippon Koki Co., Ltd., Osaka, Japan, \\ ${ }^{* 5}$ Mitsubishi Chemical Corporation, Tokyo, Japan, \\ ${ }^{* 6}$ Furukawa Electric Co., Ltd., Chiba, Japan \\ E-mail: niino.hiro@aist.go.jp
}

\begin{abstract}
We report here laser cutting of carbon fiber reinforced plastic (CFRP) with an IR fiber laser (average power: $2-3 \mathrm{~kW}$ ). The CFRP samples contain thermoplastic resin (CFRTP; carbon fiber reinforced thermo-plastic) or thermosetting resin as binding plastic. Well-defined laser cutting free of debris around the groove was performed for various type of CFRP plates by the laser irradiation with a fast beam galvanometer scanner on a multiple-scan-pass method. The laser-induced damage in the samples was observed and analyzed by microscopic X-ray Computed Tomography. Laser cutting with a high speed beam scanning exhibits a clean top and excellent sidewall quality along with a negligible heat-affected zone.
\end{abstract}

DOI: $10.2961 /$ jlmn.2016.01.0020

Keywords: laser micromachining, laser ablation, cw IR fiber laser, CFRTP and CFRP composite

\section{Introduction}

Laser-induced cutting of various materials has led to inventions of numerous industrial processes that have redefined the speed of production-line manufacturing and the strength of industrial manufacturing applications. Reliable systems composed of rapid and easy operations with excellent repeatability can be designed with solid-state lasers. The laser cutting process achieves high-precision cuts with narrow kerfs where complex contours demand precise, fast and force-free processing $[1,2]$. In particular, considerable attention has been given towards the cutting of carbon fiber reinforced plastic (CFRP) and carbon fiber reinforced thermo-plastic (CFRTP), composite materials of resin matrices and reinforced carbon fibers, since, in spite of the difficulty involved, they are high strength, and yet lightweight materials, and is increasingly being used for various applications in automotive and aerospace fields. The use of lasers for these composite materials can involve several approaches, such as fiber laser processing [3-26], UV laser processing [15, 21, 27-38], picosecond laser micromachining [39-48], femtosecond laser micromachining $[43,49,50]$, disk laser processing [51, 52], YAG laser processing [53-64], $\mathrm{CO}_{2}$ laser processing [5, 19, 22, 24-26, 57, 65-77], and theoretical model/analysis [78-84]. In addition, another advantage of laser processes is flexibility of groove shaping in accord with laser scanning tracks. To explore the possibility of 3D laser processing, cutting of CFRP for a three-dimensional molded sample was performed with a five-axis laser cutting machine [3].

In this paper, we report on the laser cutting of CFRTP and CFRP plates with a cw fiber near-IR laser $(\lambda=1084$ $\mathrm{nm})$. Well-defined cutting free of debris around the groove was achieved for CFRTP and CFRP by the laser irradiation with a fast beam galvanometer scanner on a multiple-scanpass method [3-5, 8-11, 16, 17, 36, 55, 71]. The laserinduced damage in the samples was observed to estimate heat-affected zone (HAZ), by microscopic X-ray Computed Tomography (X-CT).

\section{Experimental}

Two different types of samples of three-mm-thick CFRTP plates were employed for the laser cutting. These were prepared by injection molding (chopped PAN-type carbon fiber $(\mathrm{Cf}=30 \mathrm{wt} \%)$ in ABS-resin (ABS; co-polymer of acrylonitrile-butadiene-styrene, Toray Industries Inc.) and PPS resin (polyphenylene sulfide, Toray Industries Inc.).

Three-mm-thick CFRP plates of PAN-based carbon fiber was also used for the laser cutting. The CFRP sample used in this study was commercially available prepreg laminate consisting of thermoset epoxy resin with PANbased carbon fibers. The lamina consists of unidirectional fiber stacking parallel and perpendicular to the fiber direction (cross-ply 0/90, 12 -ply layers, $\mathrm{Cf}=70 \%$ ).

We used a near-IR laser (Furukawa Electric, Yb-doped fiber laser, wavelength $\lambda=1084 \mathrm{~nm}$, multi-mode (fiber core diameter: $50 \mu \mathrm{m}$ ), average power $\mathrm{P}=2-3 \mathrm{~kW})$. The laser was operated in the cw-mode or the qcw-mode (duty $40 \%$, repetition rate $800 \mathrm{~Hz}$ ). The laser beam on the sample surface was scanned with a galvanometer scanner by multiple-scan-pass irradiation in the air (scanning speed: $3.6 \mathrm{~m} \mathrm{~s}^{-1}$, without assist gas). The beam was focused on the laser-incident sample surface with an $\mathrm{f}$-theta lens $(\mathrm{f}=306$ $\mathrm{mm}$ ). In addition, the cutting procedure of double scanning 
line with the gap of $0.1 \mathrm{~mm}$ was also employed for the complete cutting of three-mm-thick CFRP-epoxy sample in order to acquire wide kerf width of the groove.

The internal damages of laser-cut samples were observed with a micro X-ray Computed Tomography system (Yamato Science Co.; TDM1000H-S $\mu / \mathrm{TDM} 1600 \mathrm{H}-$ II, X-ray filament: $\mathrm{LaB}_{6}$ ).

\section{Results and Discussion}

\subsection{Laser cutting property of CFRTP (thermo-plastic resin)}

The cross-sectional and 3D images of CFRTP-ABS sample after $\mathrm{cw}$ fiber laser irradiation on a multiple-scanpass method are shown in Fig. 1. Laser scanning speed was set at $3.6 \mathrm{~m} \mathrm{~s}^{-1}$. As the laser-pass-number at $\mathrm{cw} 2 \mathrm{~kW}$-laser irradiation increases, the depth of cutting grooves increases proportionally (Fig. 1(a)). In addition, the observation from the direction perpendicular to the grooves proves that the depth of a groove is uniform until the plate was completely cut. The kerf width of the groove on the laser beam incident surface is estimated to be $500 \mu \mathrm{m}$. The internal kerf of the groove in bulk region is ca. $200 \mu \mathrm{m}$, as shown in Fig. 1(a). The 3D image of CFRTP-ABS shows only a few debris deposited on the laser-incident sample surface (Fig. 1(b)) $[23,33]$.

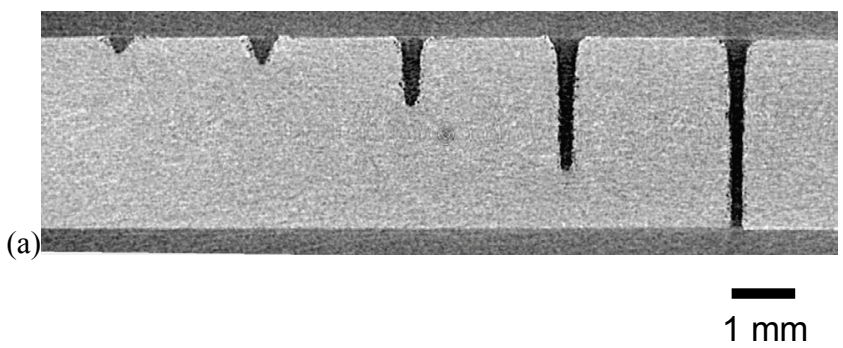

(b)

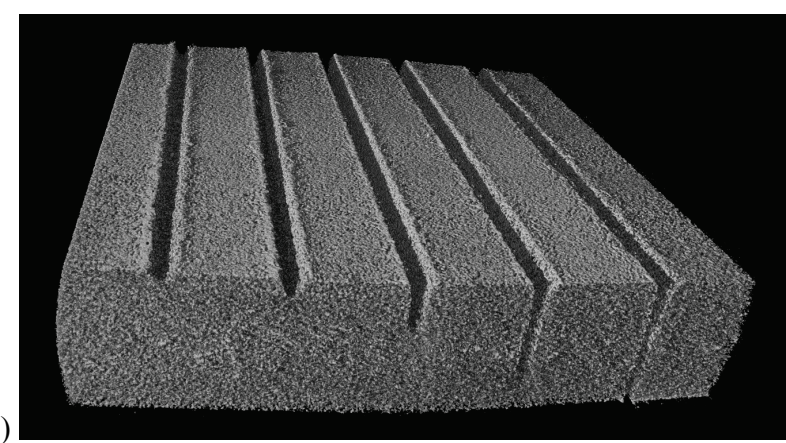

Fig. 1 X-CT image of three-mm-thick CFRTP-ABS plate cut by $\mathrm{cw}$ fiber laser irradiation on a multiple-scan-pass method. Laser scanning speed on the sample was set at $3.6 \mathrm{~m} \mathrm{~s}^{-1}$; Laser-passnumber: $1,2,5,10,15$. (a) cross-sectional image of the CFRTPABS plate, (b) volume rendering 3D-image.
Figure 2 shows the cutting depth of three-mm-thick CFRTP-PPS and CFRTP-ABS plates plotted as the function of the laser pass-number. Linear relation between the cutting depth and laser pass-number was observed for both of CFRTP-PPS and CFRTP-ABS. The complete cutting of the CFRTP-PPS and CFRTP-ABS plates required the multiple-scan-pass irradiation of 27 passes and 15 passes, respectively, at the scanning speed of $3.6 \mathrm{~m} \mathrm{~s}^{-1}$ at cw $2 \mathrm{~kW}$-laser irradiation.

We have already reported that other types of CFRTP in the resin of, such as, polycarbonate (CFRTP-PC) and polyamide (CFRTP-PA, nylon6) also indicate the linear relation with the fiber laser irradiation [3, 8-10]. The above results indicate that constant etching rate as far as the thickness of $3 \mathrm{~mm}$ was acquired for various CFRTP samples; the depth of a groove of CFRTP samples can be precisely controlled by the laser pass-number.

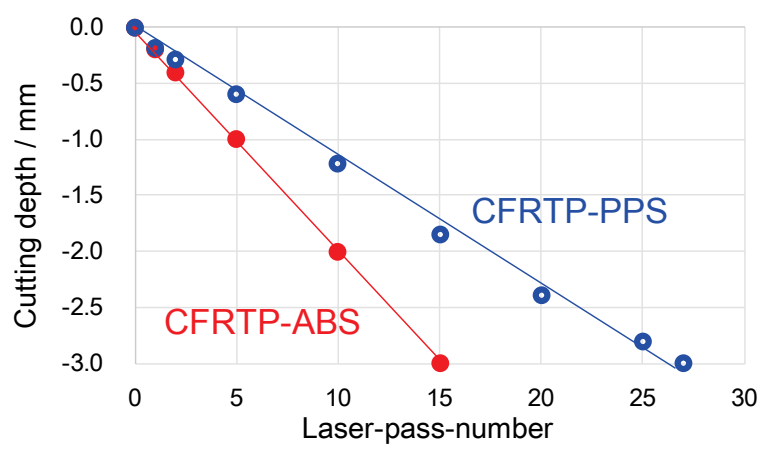

Fig. 2 Cutting depth of the three-mm-thick CFRTP plates by $\mathrm{cw}$ fiber laser irradiation on a multiple-scan-pass method (cw $2 \mathrm{~kW}$ laser irradiation). Laser scanning speed was set at $3.6 \mathrm{~m} \mathrm{~s}^{-1}$; redcolored circle: CFRTP-ABS (ABS resin), blue-colored circle: CFRTP-PPS (polyphenylene sulfide)

High resolution X-CT images of the CFRTP-ABS and CFRTP-PPS samples are shown in Figs. 3 and 4. The internal kerf of the groove in the bulk region is ca. $200 \mu \mathrm{m}$, as shown in Fig. 3(a), so that the aspect ratio of the groove is ca. 15. Figure 4(a) indicates that the internal kerf of CFRTP-PPS is ca. $100-200 \mu \mathrm{m}$.

Cross-sectional image of Fig. 3(a) clearly shows the formation of micron-sized voids (dark spots in the image) in the subsurface of internal wall at the groove. As the micron-sized voids are produced by thermal damage during the laser irradiation, the voids are present on the entire surface of the internal wall (Fig. 3(b)). It is worth noted that the micron-sized voids appear only within the $100-\mu \mathrm{m}-$ thick surface layer of the internal wall of the groove, suggesting that thermal damage as HAZ (heat-affected zone) during the laser irradiation of the CFRTP-ABS sample was effectively suppressed. The formation of micron-sized voids of CFRTP-PPS sample was observed within the $130-\mu m$-thick surface layer of the internal wall of the groove (Fig. 4(a)). Laser irradiation on CFRTP-PC and CFRTP-PA also induces micron-sized void formation within the $100-\mu \mathrm{m}$-thick surface layer of the internal wall of the groove [3, 8-10]. 


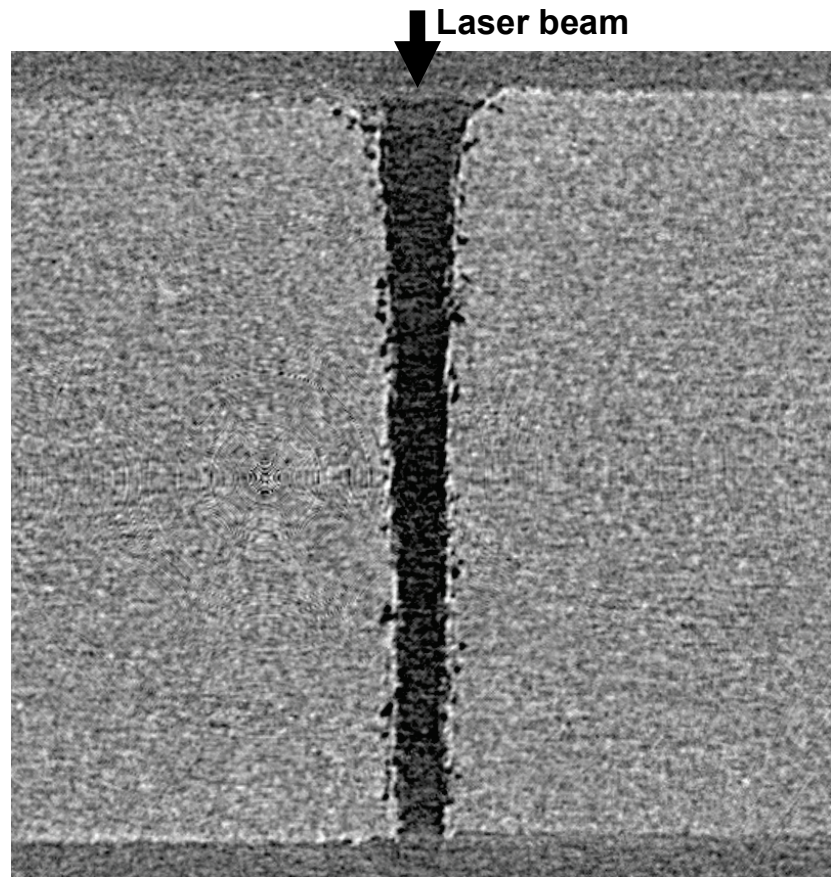

(a)

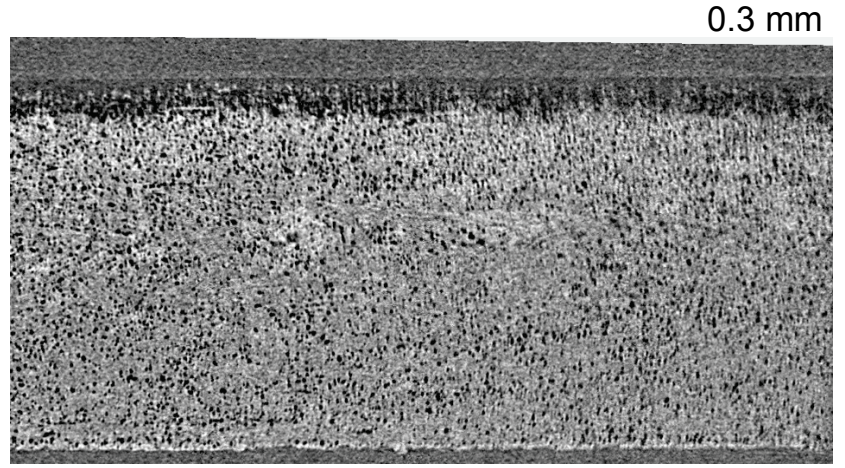

(b)

$0.5 \mathrm{~mm}$

Fig. 3 High-resolution X-CT images of the three-mm-thick CFRTP-ABS plate; (a) cross-sectional image, (b) cutting-surface image. The sample was cut by $\mathrm{cw}$ fiber laser irradiation at the 2 $\mathrm{kW}$ average power with the scanning speed of $3.6 \mathrm{~m} \mathrm{~s}^{-1}$ and 15 passes.

\subsection{Laser cutting property of CFRP (thermoset epoxy resin)}

Cutting depth of the three-mm-thick CFRP-Epoxy plate (PAN carbon fiber, thermoset epoxy resin) was plotted as the function of the laser pass-number for $\mathrm{cw} 3.3$ $\mathrm{kW}$-laser irradiation (Fig. 5). The cutting rate for the single-line cutting was fast and constant for the first 1-15 passes (ca. $2 \mathrm{~mm}$ in 15 passes), and rapidly decreased for the 15-40 passes. The cutting depth was almost saturated for the 40-50 passes, resulting in incomplete cut of the sample plate. This would be because of the narrow kerf of this case, which causes bottom disturbance. The kerf width of the groove on the laser beam incident surface is estimated to be $350 \mu \mathrm{m}$, as shown in Fig. 6(a). The internal kerf of the groove in the bulk region is $0-100 \mu \mathrm{m}$. Similar suppression of cutting rate was observed for the single-line cutting of two-mm-thick CFRP-Epoxy plates [3].

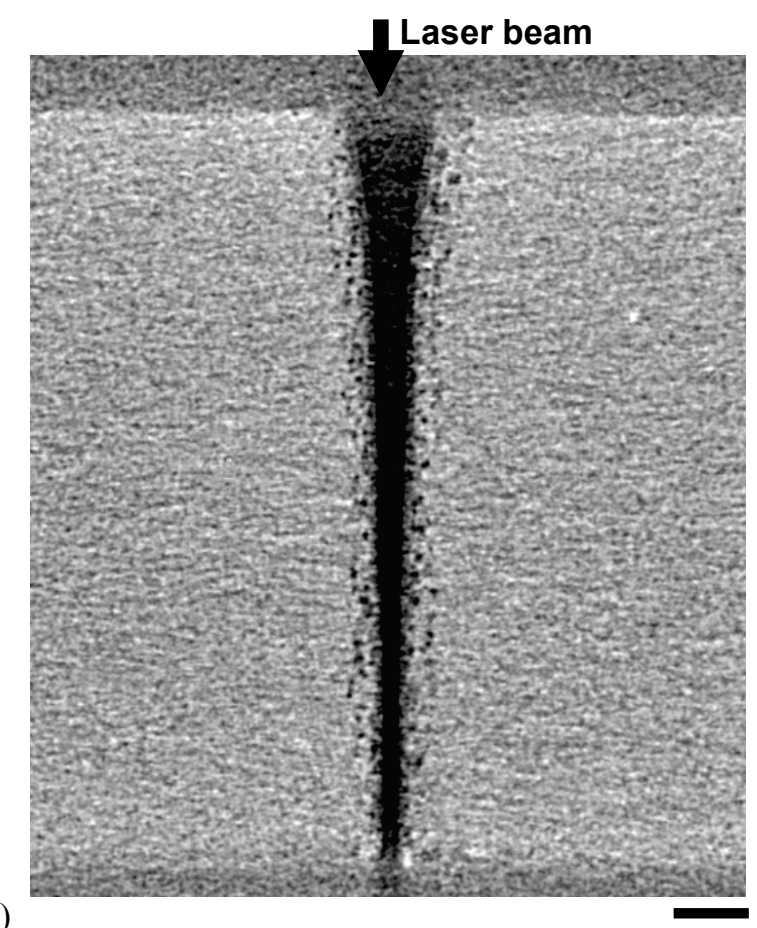

(a)

$0.3 \mathrm{~mm}$

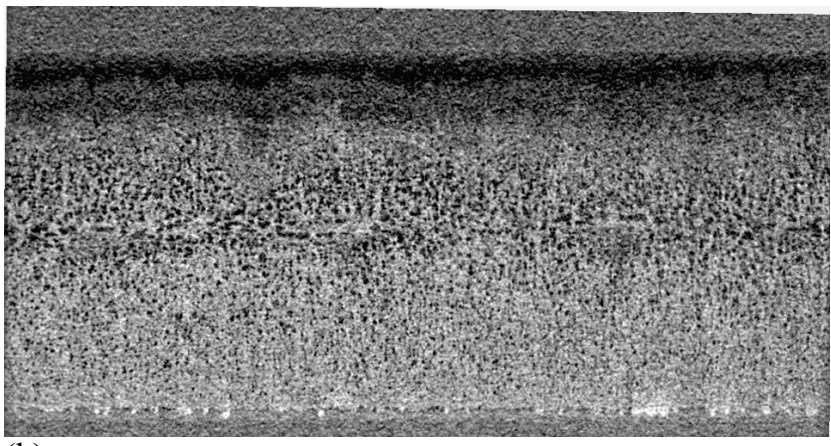

(b)

$0.5 \mathrm{~mm}$

Fig. 4 High-resolution cross-sectional X-CT images of the threemm-thick CFRTP-PPS plate; (a) cross-sectional image, (b) cutting-surface image. The sample was cut by $\mathrm{cw}$ fiber laser irradiation at the $2 \mathrm{~kW}$ average power with the scanning speed of $3.6 \mathrm{~m} \mathrm{~s}^{-1}$ and 27 passes.

The three-mm-thick CFRP sample was successfully cut at cw $3.3 \mathrm{~kW}$ by scanning the laser in a doubly line with a gap of $0.1 \mathrm{~mm}$. The kerf width of the groove on the laser beam incident surface is estimated to be $450 \mu \mathrm{m}$. The internal kerf of the groove in the bulk region is ca. 150-100 $\mu \mathrm{m}$, as shown in Fig. 6(b). These results indicate that sufficient kerf width is required for effective etching of CFRP. In other words, combination of double-line scanning and multiple-scan-pass irradiation of 50 passes with the scanning speed of $3.6 \mathrm{~m} \mathrm{~s}^{-1}$ enables fine and complete cutting of a CFRP plate as thick as $3 \mathrm{~mm}$ at the average power as small as $3.3 \mathrm{~kW}$. 


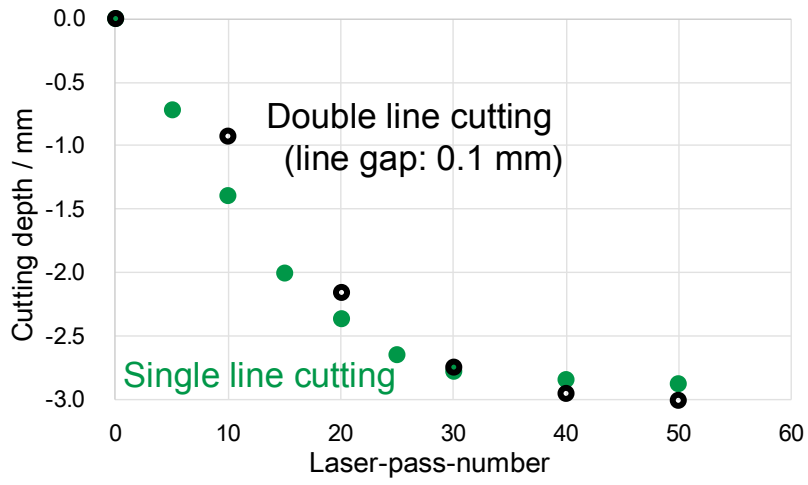

Fig. 5 Cutting depth of the three-mm-thick CFRP-Epoxy plate by $\mathrm{cw}$ fiber laser irradiation on a multiple-scan-pass method (cw $3.3 \mathrm{~kW}$-laser irradiation). Scanning speed was set at $3.6 \mathrm{~m} \mathrm{~s}^{-1}$; green-colored circle: single line cutting, black-colored circle: double line cutting (line gap: $0.1 \mathrm{~mm}$ ). (a)

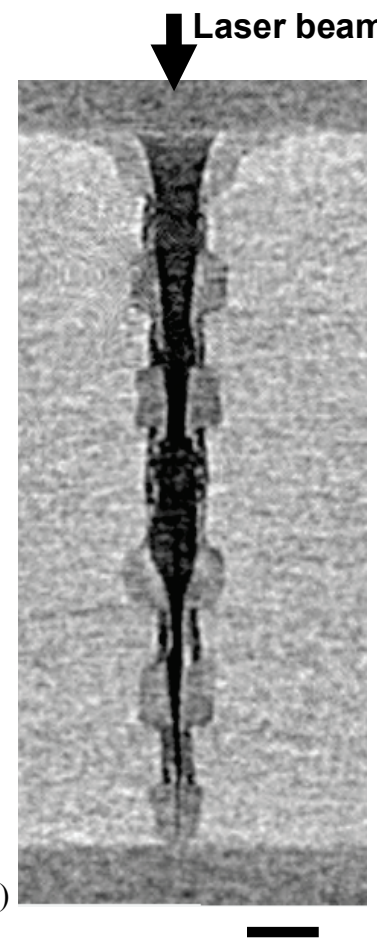

$0.3 \mathrm{~mm}$

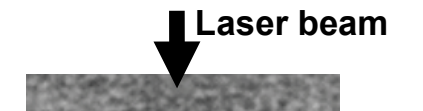

(b)

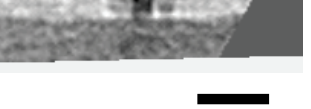

$0.3 \mathrm{~mm}$

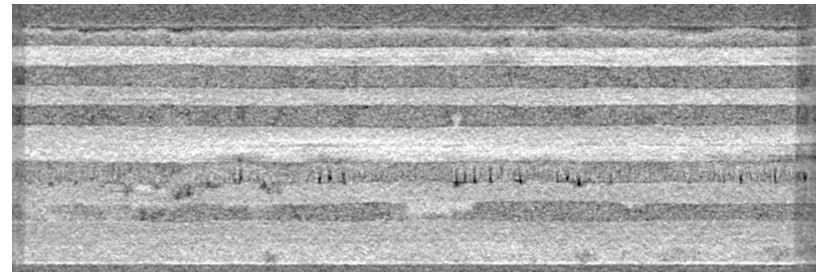

(c)

$0.5 \mathrm{~mm}$

Fig. 6 High-resolution $\mathrm{X}-\mathrm{CT}$ images of the three-mm-thick CFRP-Epoxy plate. The sample was cut by cw fiber laser irradiation of $3.3 \mathrm{~kW}$ average power with the scanning speed of $3.6 \mathrm{~m} \mathrm{~s}^{-1}$ and 50 passes; (a) cross-sectional image of single line cutting, (b) cross-sectional image of double line cutting (line gap: $0.1 \mathrm{~mm}$ ), (c) cutting surface of double line cutting. (a)

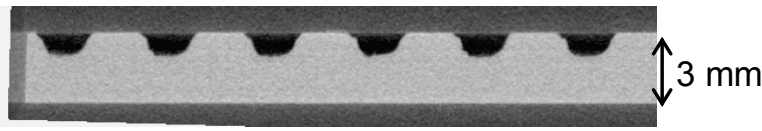

(b)

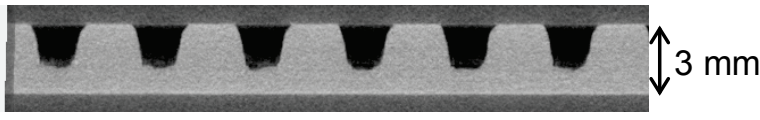

(c)

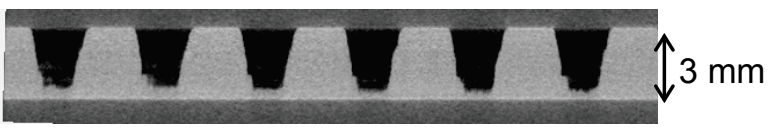

(d)

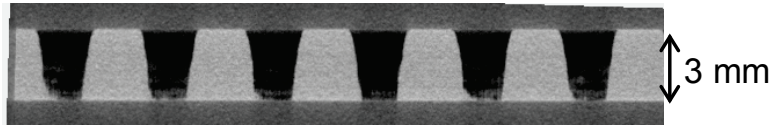

(e)

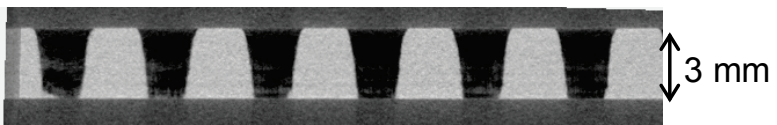

(f)
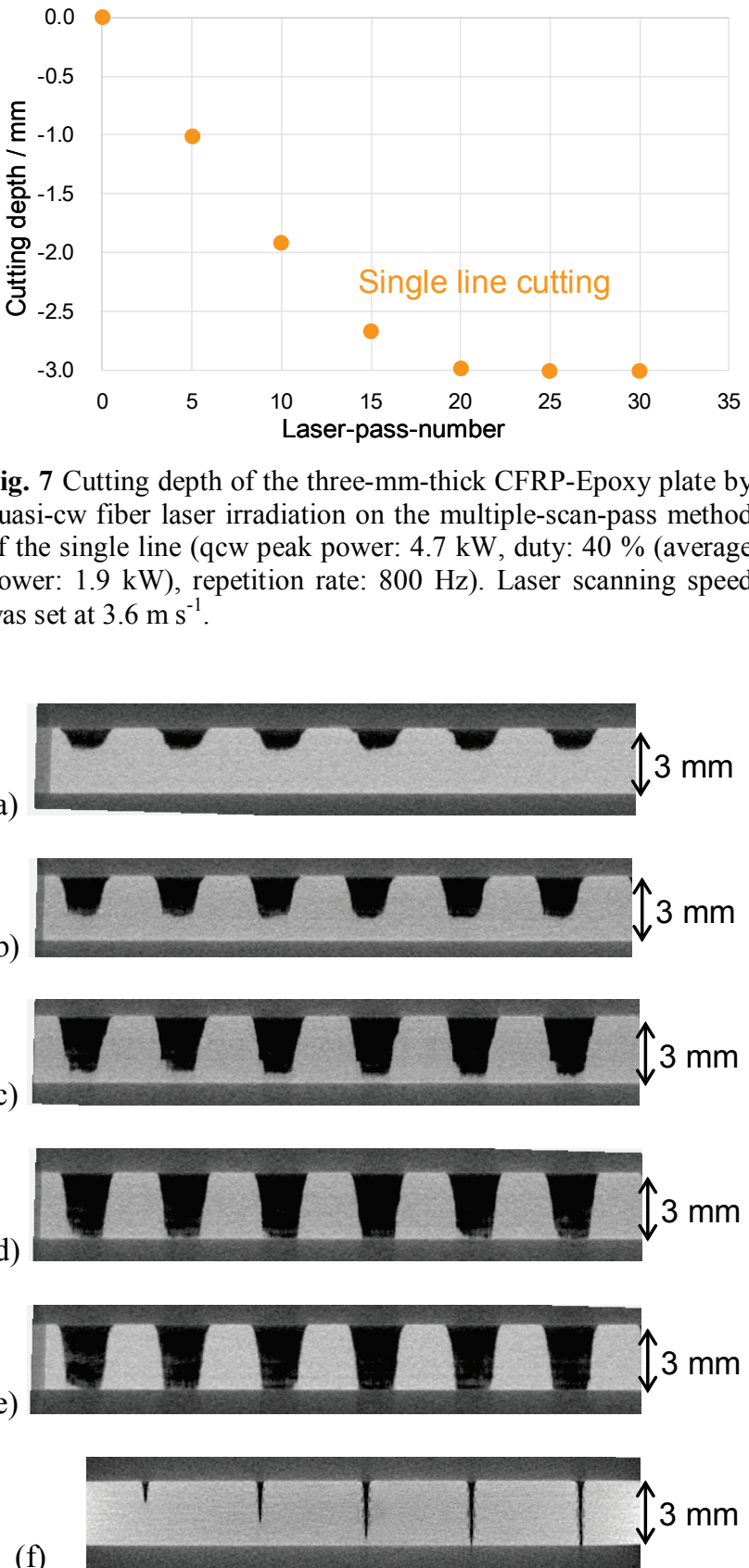

Fig. 7 Cutting depth of the three-mm-thick CFRP-Epoxy plate by quasi-cw fiber laser irradiation on the multiple-scan-pass method ( was set at $1.9 \mathrm{~kW})$, repc

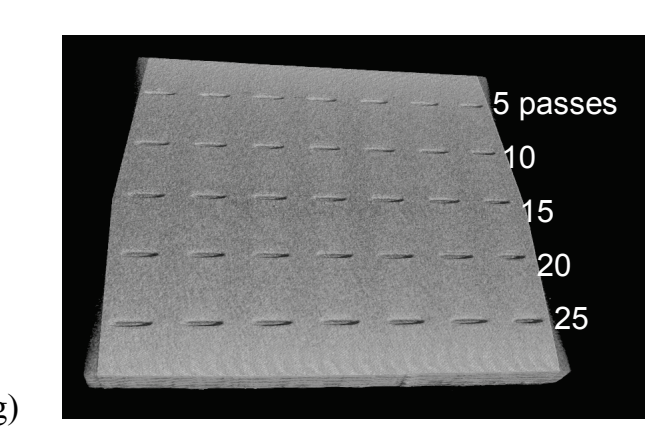

Fig. 8 X-CT images of the three-mm-thick CFRP-Epoxy plate. The sample was cut by qcw fiber laser irradiation of $4.7 \mathrm{~kW}$ peak power with the scanning speed of $3.6 \mathrm{~m} \mathrm{~s}^{-1}$ (duty: $40 \%$ (average power: $1.9 \mathrm{~kW}$ ), repetition rate: $800 \mathrm{~Hz}$ ); Cross-sectional X-CT image at parallel to the scanning direction (a) 5, (b) 10, (c) 15, (d) 20, (e) 25 passes, (f) Cross-sectional images perpendicular to the scanning direction with $5,10,15,20,25$ passes, (g) Volume rendering $3 \mathrm{D}$ images. 


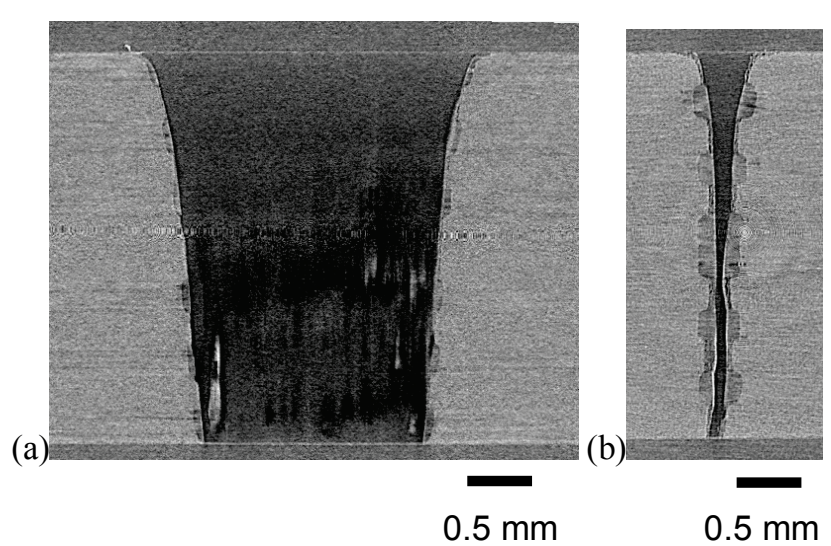

Fig. 9 High-resolution cross-sectional X-CT images of the threemm-thick CFRP-Epoxy plate at two different observation directions. The sample was cut by qcw fiber laser irradiation of $4.7 \mathrm{~kW}$ peak power with the scanning speed of $3.6 \mathrm{~m} \mathrm{~s}^{-1}$ and 30 passes, (a) Cross-sectional image parallel to the scanning direction, (b) Cross-sectional image perpendicular to the scanning direction.

In Fig. 6, fiber-pull-out and resin-matrix recession are clearly observed. Both the phenomena depend on the direction of fiber long axis with respect to the scanning direction of the laser beam [3,16]. Figure 6 also shows dark areas of the cutting surface of CFRP-Epoxy sample. The thickness of this dark areas was estimated to be 150 $\mu \mathrm{m}$ as a maximum along the lateral direction of the sample plate. The areas are attributed to the thermal damage of resin matrix.

Upon the laser irradiation with the quasi-cw mode, the peak power of the fiber laser increases up to $4.7 \mathrm{~kW}$ at a duty of $40 \%$ and a repetition rate of $800 \mathrm{~Hz}$ (average power: $1.9 \mathrm{~kW}$ ). Cutting depth of the three-mm-thick CFRP-Epoxy plate was plotted as the function of the laser pass-number at qcw laser irradiation (Fig. 7). After the 2530 passes of laser irradiation, full cutting of the sample was completed with the cutting procedure of single line (Fig. 8). At the 15 to 30 passes, the etching rate per pass was gradually saturated. The kerf width of the groove on the laser beam incident surface is estimated to be $450 \mu \mathrm{m}$. The internal kerf of the groove in the bulk region is ca. $100 \mu \mathrm{m}$.

The depth of dark areas at the cutting surface of CFRPEpoxy sample was estimated to be $150 \mu \mathrm{m}$ as a maximum for the lateral direction analyzed from the X-CT images at two different observation direction, as shown in Fig. 9. The above results shows that the kerf width of the groove on the surface of CFRP-Epoxy was strongly dependent on the laser power incident onto the sample [3, 57, 69].

\section{Summary}

We have performed micro-cutting of CFRP in ambient air upon a multiple-scan-pass irradiation with a cw near-IR laser. Laser cutting with high speed beam scanning exhibits a clean top and excellent sidewall quality along with a negligible HAZ. It was confirmed that the pulse power is an important parameter for the complete cutting of a CFRP-Epoxy plate with a thickness of $3 \mathrm{~mm}$.

\section{Acknowledgments}

This work was supported in part by the national project of "Advanced Laser and Processing Technology for Nextgeneration Materials Project" (High-power Pulsed Fiber Laser and Processing Technology Project) launched in 2010FY (period: 5 years) in Industrial Technology Center of NEDO.

\section{References}

[1] K. Sugioka, M. Meunier, and A. Piqué, (Eds.): "Laser Precision Microfabrication, Springer Series in Materials Science, Vol. 135”, (Springer-Verlag, Berlin \& Heidelberg, 2010).

[2] D. Bauerle: "Laser Processing and Chemistry (4th Ed.)", (Springer-Verlag, Berlin \& Heidelberg, 2011).

[3] H. Niino, Y. Harada, K. Anzai, M. Aoyama, M. Matsushita, K. Furukawa, M. Nishino, A.Fujisaki, T. Miyato, and T. Kayahara: Proc. of SPIE, 9353, (2015) p.935303.

[4] M. Muramatsu, Y. Harada, T. Suzuki, and H. Niino: Advanced Composite Materials, DOI: 10.1080/ 09243046.2014.986844 (2015).

[5] M. Muramatsu, Y. Harada, T. Suzuki, and H. Niino: Composites: Part A, A68, (2015) 242.

[6] S. Bluemel, R. Staehr, P. Jaeschke, O. Suttmann, and L. Overmeyer: J. of Reinforced Plastics and Composites, 34(8), (2015) 662.

[6] D. Herzog, M. Schmidt-Lehr, M. Canisius, M. Oberlander, J.-P. Tasche, and C. Emmelmann: J. of Laser Applications, 27(S2), (2015) S28001.

[8] H. Niino, Y. Kawaguchi, T. Sato, A. Narazaki, R. Kurosaki, M. Muramatsu, Y. Harada, K. Wakabayashi, T. Nagashima, Z. Kase, M. Matsushita, K. Furukawa, and M. Nishino: JLMN-Journal of Laser Micro/Nanoengineering, 9, (2014) 180.

[9] H. Niino, Y. Kawaguchi, T. Sato, A. Narazaki, R. Kurosaki, M. Muramatsu, Y. Harada, K. Wakabayashi, T. Nagashima, Z. Kase, M. Matsushita, K. Furukawa, M. Nishino, A.Fujisaki, T. Miyato, and T. Kayahara: Proc. of LPM2014 - the 15th International Symposium on Laser Precision Microfabrication, Vilnius, (2014) p.\#14-33.

[10] H. Niino, Y. Kawaguchi, T. Sato, A. Narazaki, R. Kurosaki, M. Muramatsu, Y. Harada, K. Anzai, M. Aoyama, M. Matsushita, K. Furukawa, M. Nishino, A.Fujisaki, T. Miyato, and T. Kayahara: Proc. of SPIE, 8967, (2014) p.89670J.

[11] H. Niino, Y. Kawaguchi, T. Sato, A. Narazaki, R. Kurosaki, Y. Harada, M. Muramatsu, K. Wakabayashi, T. Nagashima, Z. Kase, M. Matsushita, K. Furukawa, and M. Nishino: Proc. of SPIE, 8607, (2013) p.860714.

[12] A. N. Fuchs, M. Schoeberl, J. Tremmer, and M.F. Zaeh: Physics Procedia, 41, (2013) 372.

[13] S. Bluemel, R. Staehr, P. Jaeschke, and U. Stute: Physics Procedia, 41, (2013) 401.

[14] T. Miyato, T. Kayahara, A. Fujisaki, K. Furukawa, M. Matsushita, M. Muramatsu, Y. Harada, and H. Niino: Proc. of SPIE, 8963, (2014) p.89630W.

[15] K. Anzai, M. Aoyama, A. Fujisaki, T. Miyato, T. Kayahara, Y. Harada, and H. Niino: Proc. of SPIE, 8967, (2014) p.89670K. 
[16] C. Leone, S. Genna, and V. Tagliaferri: Optics and Lasers in Engineering, 53, (2014) 43.

[17] C. Leone, I. Papa, F. Tagliaferri, and V. Lopresto: Composites: Part A, 55, (2013) 129.

[18] K. Furukawa, M. Matsushita, Y. Harada, T. Nagashima, and H. Niino: Proc. of International Symposium on Laser Processing of CFRP and Composites (LPCC-2013), Yokohama, vol. LPCC2013-5(3), (2013) p.1.

[19] M. Nishino, Y. Harada, T. Nagashima, M. Matsushita, and H. Niino: Proc. of International Symposium on Laser Processing of CFRP and Composites (LPCC2013), Yokohama, vol. LPCC2013-5(4), (2013) p.1.

[20] M. Muramatsu, Y. Harada, T. Suzuki, and H. Niino: Proc. of International Symposium on Laser Processing of CFRP and Composites (LPCC-2013), Yokohama, vol. LPCC2013-5(5), (2013) p.1.

[21] H. Niino, Y. Kawaguchi, T. Sato, A. Narazaki, R. Kurosaki, Y. Harada, T. Nagashima, Z. Kase, M. Matsushita, K. Furukawa, and M. Nishino: Proc. of International Symposium on Laser Processing of CFRP and Composites (LPCC-2012), Yokohama, vol. LPCC2012-4(5), (2012) p.1.

[22] Y. Harada, T. Suzuki, M. Nishino, and H. Niino: Proc. of International Symposium on Laser Processing of CFRP and Composites (LPCC-2012), Yokohama, vol. LPCC2012-4(4), (2012) p.1.

[23] H. Niino: Proc. of 31st International Congress on Applications of Lasers \& Electro-Optics, C105, (2012) p.31.

[24] M. Nishino, Y. Harada, T. Suzuki, and H. Niino: Proc. of SPIE, 8243, (2012) p.82431C.

[25] Y. Harada, K. Kawai, T. Suzuki, and T. Teramoto: Materials Science Forum, vol.706-709, (2012) p.649.

[26] A. Goeke and C. Emmelmann: Physics Procedia 5, (2010) 253.

[27] A. Narazaki, T. Sato, Y. Kawaguchi, and H. Niino: JLMN-Journal of Laser Micro/Nanoengineering, 9 (1), (2014) 59.

[28] H. Dittmar, F. Gäbler, and U. Stute: Physics Procedia, 41, (2013) 266.

[29] S. Kreling, F. Fischer, R. Delmdahl, F. Gäbler, and K. Dilger: Physics Procedia, 41, (2013) 282.

[30] F. Völkermeyer, P. Jaeschke, U. Stute, and D. Kracht: Applied Physics A, A112, (2013) 179.

[31] Y. Kawaguchi, T. Sato, A. Narazaki, R. Kurosaki, and H. Niino: Proc. of the 2nd International Symposium on Laser Processing of CFRP and Composites (LPCC-2013), Yokohama, vol. LPCC2013-4(2), (2013) p.1.

[32] F. Fischer, S. Kreling, and K. Dilger: Physics Procedia, 39, (2012) 154.

[33] H. Niino and R. Kurosaki: Proc. of SPIE, 7920, (2011) p.792019.

[34] F. Völkermeyer, F. Fischere, U. Stute, and D. Kracht: Physics Procedia, 12, (2011) 537.

[35] Z. L. Li, H. Y. Zheng, G. C. Lim, P. L. Chu, and L. Li: Composites Part A: Applied Science and Manufacturing, 41, (2010) 1403.

[36] Z. L. Li, P. L. Chu, H. Y. Zheng, and G. C. Lim: SIMTech technical reports, 10, (2009) 10.
[37] A. Hartwig, G. Vitr, and V. Schlett: International J. of Adhesion and Adhesives, 17, (1997) 373.

[38] H. Niino, M. Nakano, S. Nagano, H. Nitta, K. Yano, and A. Yabe: J. of Photopolymer Science and Technology, 3, (1990) 53.

[39] C. Freitag, M. Wiedenmann, J.-P. Negel, A. Löscher, V. Onuseit, R. Weber, M. Abdou Ahmed, and T. Graf: Appl. Phys. A, 119, (2015) 1237.

[40] V. Onuseit, C. Freitag, M. Wiedenmann, R. Weber, J.P. Negel, A. Löscher, M. Abdou Ahmed, and T. Graf: Proc. of SPIE, 9350, (2015) p.935012.

[41] T. V. Kononenko, C. Freitag, M. S. Komlenok, V. Onuseit, R. Weber, T. Graf, and V. I. Konov: J. Appl. Phys., 115, (2014) 103107_1-7.

[42] R. Weber, T. Graf, P. Berger, V. Onuseit, M. Wiedenmann, C. Freitag, and A. Feuer: Optics Express, 22, (2014) 11312.

[43] N. Schilling, A. Lasagni, and U. Klotzbach: Physics Procedia, 41, (2013) 414.

[44] J. Finger, M. Weinand, and D. Wortmann: J. of Laser Application, 25, (2013) 042007 1-5.

[45] R. Weber, C. Freitag, T. Kononenko, M. Hafner, V. Oniseit, P. Berger, and T. Graf: Physics Procedia, 39, (2012) 137.

[46] C. Freitag, V. Oniseit, R. Weber, and T. Graf: Physics Procedia, 39, (2012) 137.

[47] A. Wolynski, T. Herrmann, P. Mucha, H. Haloui, and J. L'huillier: Physics Procedia 12, (2011) 292.

[48] C. Emmelmann, M. Petersen, A. Goeke, and M. Canisius: Physics Procedia 12, (2011) 565.

[49] M. Fujita, T. Somekawa, and N. Miyanaga: Physics Procedia, 41, (2013) 629.

[50] J. Kruger and W. Kautek: Applied Surface Science, 106, (1996) 383.

[51] K.-W. Jung, Y. Kawahito, and S. Katayama: J. of Laser Applications, 24, (2012) 012007_1-8.

[52] M. Jarwitz, V. Onuseit, R. Weber, and T. Graf: Physics Procedia, 41, (2013) 489.

[53] A. Fürst, A. Klotzbach, S. Hühne, J. Hauptmann, and E. Beyer: Physics Procedia, 41, (2013) 382.

[54] M.S.F. Lima, J.M.S. Sakamoto, J.G.A. Simoes, and R. Riv: Physics Procedia, 41, (2013) 565.

[55] J. Stock, M. F. Zaeh, and M. Conrad: Physics Procedia, 39, (2012) 161.

[56] R. Negarestani, L. Li, H. K. Sezer, D. Whitehead, and J. Methven: International J. of Advanced Manufacturing Technology, 49, (2010) 553.

[57] D. Herzog, P. Jaeschke, O. Meier, and H. Haferkamp: International J. of Machine Tools \& Manufacture, 48, (2008) 1464

[58] T. M. Young: J. of Thermoplastic Composite Materials, 21, (2008) 543.

[59] R. E. Litchfielda, G. W. Critchlowa, and S. Wilson: International J. of Adhesion \& Adhesives, 26, (2006) 295.

[60] T. Young, B. Mahony, B. Humphreys, E. Totland, A. McMlafferty, and J. Corish: Aerospace Science and Technology , 7, (2003) 181.

[61] T. Young and D. O'Driscoll: Composites Part A: Applied Science and Manufacturing, 33, (2002) 1.

[62] W. S. O. Rodden, S. S. Kudesia, D. P. Hand, and J. D. C. Jones: Optics Communications, 210, (2002) 319. 
[63] J. Mathew, G. L. Goswami, N. Ramakrishnan, and N. K. Naik: J. of Materials Processing Technology, 8990, (1999) 198.

[64] C. F. Cheng, Y. C. Tsui, and T. W. Clyne: Acta Materialia, 46, (1998) 4273.

[65] P. Mucha, P. Berger, R. Weber, N. Speker, B. Sommer, and T. Graf: Appl. Phys. A, 118, (2015) 1509 .

[66] S. Nagesh, H. N. Narasimha Murthy, Ratna Pal, M. Krishna, and B. S. Satyanarayana: Optics \& Laser Technology, 69, (2014) 23.

[67] Y. Harada, M. Muramatsu, T. Suzuki, M. Nishio, and H. Niino: Materials Science Forum, 783-786, (2014) 1518.

[68] F. Schneider, N. Wolf, and D. Petring: Physics Procedia, 41, (2013) 408.

[69] P. Mucha, N. Speker, R. Weber, and T. Graf: Appl. Phys. A., 113, (2013) 361.

[70] A. Riveiro, F. Quintero, F. Lusquiños, J. del Val, R. Comesaña, M. Boutinguiza, and J. Pou: Composites: Part A, 43, (2012) 1400.

[71] A. Klotzbach, M. Hauser, and E. Beyer: Physics Procedia, 12, (2011) 572.

[72] F. A. Al-Sulaiman, B. S. Yilbas, and M. Ahsan: J. of Materials Processing Technology, 173, (2006) 345.

[73] T. J. Matthams and T. W. Clyne: Composites Science and Technology, 59, (1999) 1169.
[74] T. J. Matthams and T. W. Clyne: Composites Science and Technology, 59, (1999) 1181.

[75] E. Uhlmann, G.Spur, H. Hocheng, S. Leibelt, and C. T. Pan: International J. of Machine Tools \& Manufacture, 39, (1999) 639.

[76] A. Hartwig, G. Vitr, S. Dieckhoff, and O.-D. Hennemann: Die Angewandte Makromolekulare Chemie, 238, (1996) 177.

[77] V. Tagliaferri, A. Di Ilio, and C.Visconti: Composites, 16, (1985) 317

[78] R. D. Chippendale, I. O. Golosnoy, and P. L. Lewin: J. Phys. D: Appl. Phys. 47, (2014) 385301_1-15.

[79] C. Freitag, R. Weber, and T. Graf: Optics Express, 22, (2014) 1474

[80] R. Weber, M. Hafner, A. Michalowski, and T. Graf: Physics Procedia 12, (2011) 302.

[81] A. A. Cenna and P. Mathew: International J. of Machine Tools \& Manufacture, 42, (2002) 105.

[82] C. T. Pan and H. Hocheng: Composites: Part A, 32, (2001) 1657.

[83] A. A. Cenna and P. Mathew: International J. of Machine Tools \& Manufacture, 37, (1997) 723.

[84] G. Caprino and V. Tagliaferri: International J. of Machine Tools \& Manufacture, 28, (1988) 389.

(Received: July 2, 2015, Accepted: January 29, 2016) 